\title{
Gene Arrangement and Sequence of the 5S rRNA in Filobasidiella neoformans (Cryptococcus neoformans) as a Phylogenetic Indicator
}

\author{
KYUNG J. KWON-CHUNG* AND YUN C. CHANG \\ Laboratory of Clinical Investigation, National Institute of Allergy and Infectious Diseases, \\ National Institutes of Health, Bethesda, Maryland 20892
}

\begin{abstract}
We cloned the 5S rRNA gene and determined its organization in the four genes encoding rRNAs in a ribosomal DNA repeat unit of Filobasidiella neoformans, the teleomorph of Cryptococcus neoformans. The 5S rRNA gene contained 118 nucleotides and was located $1 \mathrm{~kb}$ upstream from the 18S rRNA gene within the 8.6-kb fragment of the ribosomal DNA repeat unit. The sequence of the 5S rRNA gene from $F$. neoformans was more similar to the sequence of the 5S rRNA gene from Tremella mesenterica than to the sequences of the 5S rRNA genes from Filobasidium species. The arrangement of the rRNA genes in $F$. neoformans closely resembles the arrangement of the rRNA genes in mushrooms such as Schizophyllum commune, Agaricus bisporus, and Coprinus cinereus in that the 5S rRNA-coding region not only is located within the repeat unit that encodes the other rRNAs but also is transcribed in the same direction as the other rRNA genes. This is the first description of the arrangement of rRNA genes in a species belonging to the Heterobasidiomycetes.
\end{abstract}

In 1989 , the gene cluster encoding rRNAs in a strain of Cryptococcus neoformans was cloned by Restrepo and Barbour, who used a ribosomal DNA (rDNA) clone of Saccharomyces cerevisiae as a probe (21). The arrangement of rDNA subunits within this $8.6-\mathrm{kb}$ cloned fragment was determined to be $18 \mathrm{~S}-5.8 \mathrm{~S}-25 \mathrm{~S}$, a universal pattern in all other eukaryotes that have been characterized (reviewed in reference 17). Restrepo and Barbour were unable to determine the position of the $5 \mathrm{~S}$ rRNA gene, but they postulated that it was adjacent to the $5.8 \mathrm{~S}$ rRNA gene. The $18 \mathrm{~S}, 5.8 \mathrm{~S}$, and $25 \mathrm{~S}$ rRNA genes are transcribed by RNA polymerase I as one primary transcript that is subsequently processed into the mature rRNAs prior to release from the nucleus. The 5S rRNA gene, on the other hand, is transcribed by RNA polymerase III without any subsequent processing $(20,36)$. In fungi, the location of the $5 \mathrm{~S}$ rRNA gene varies, but this gene has never been shown to be in the same region as the 5.8S rRNA gene. For example, the $5 \mathrm{~S}$ rRNA gene in Neurospora crassa $(12,23)$, Aspergillus nidulans (5), Cochliobolus heterostrophus (13), Yarrowia lipolytica (27), or Schizosaccharomyces pombe (25) is not part of the rDNA cluster and is distributed throughout the genome. In other fungi, the 5S rRNA gene is part of a tandemly repeated rDNA cluster $(6,8,9,11,19,30-32)$. In these cases, the 5S rRNA gene is located outside the $18 \mathrm{~S}-5.8 \mathrm{~S}-25 \mathrm{~S}$ rRNA transcriptional unit and is transcribed either in the same direction as the other three rRNA genes or in the opposite direction (reviewed in reference 13 ).

We cloned the 5S rRNA gene from Filobasidiella neoformans by using an oligonucleotide probe which was constructed on the basis of conserved DNA sequences found in other fungi related to Filobasidiella neoformans. The map location of the 5S rRNA gene was identified, and its organization compared with the organization of the other three rRNA genes in the rDNA repeat unit was clearly defined.

\footnotetext{
* Corresponding author. Mailing address: LCI, NIAID Building 10 Room 11C304, National Institutes of Health, Bethesda, MD 20892. Phone: (301) 496-1602. Fax: (301) 480-0050. Electronic mail address: JKC@d10.NIAID.NIH.GOV.
}

\section{MATERIALS AND METHODS}

DNA extraction. The genomic DNA of Cryptococcus neoformans was extracted by using the method of Varma and Kwon-Chung (28), with slight modifications. The yeast cells were grown overnight on plates containing yeast nitrogen base agar (Difco Laboratories, Detroit, Mich.) supplemented with $2 \%$ glucose instead of in YEPD broth (2\% glucose, $2 \%$ peptone, $1 \%$ yeast extract). The lysing solution contained 0.1 $M$ EDTA instead of 0.45 M EDTA.

DNA probe and Southern blot analysis. A probe consisting of 47 nucleotides (TTAGTACCACGGTGGGGGACCA CGCGGGAATCCTAGGTGCTGTGGTT) was synthesized on the basis of the sequences in a highly conserved region of $5 \mathrm{~S}$ rRNA that has been characterized in several heterobasidiomycetous yeasts, Filobasidium floriforme, Filobasidium capsuligenum, and Tremella mesenterica (34). The oligonucleotide sequences ranged from position 71 to position 118 of the $5 \mathrm{~S}$ rRNA genes of the two Filobasidium species. Genomic DNA from a strain of Filobasidiella neoformans, strain ATCC 34873 (= B-3501), was digested with endonucleases and electrophoresed on a $1 \%$ agarose gel. The DNA was then transferred to a nylon membrane (Hybond-N; Amersham, Arlington Hights, Ill.). The 47-mer oligonucleotide was $5^{\prime}$ end labeled by using T4 polynucleotide kinase and $\left[\gamma^{32}\right.$ P]ATP (Amersham). The 8.6-kb DNA fragment of Cryptococcus neoformans containing the rDNA repeat unit (pBIR6; obtained from B. I. Restrepo) was radiolabeled by using a random priming kit (Stratagene, La Jolla, Calif.) and $\left[\alpha^{-32} \mathrm{P}\right] \mathrm{dCTP}$ (Amersham). The membranes were then hybridized, washed, and exposed to $\mathrm{X}$-ray film as previously described (29).

Pulsed-field electrophoresis. Agarose plugs containing chromosomes from Cryptococcus neoformans isolates were prepared and electrophoresed with a contour-clamped homogeneous electric field (CHEF) gel system by using the procedure described previously (37). The separated chromosomes were transferred to a nylon membrane and hybridized with radiolabeled probes as described above.

DNA sequencing. DNA sequencing was performed by the dideoxy method by using a Sequenase version 2.0 kit obtained from U.S. Biochemicals, Cleveland, Ohio. 
A
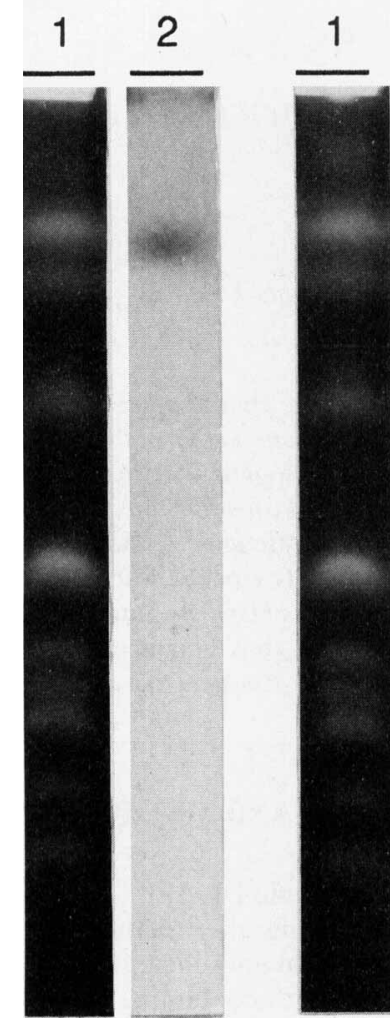

A

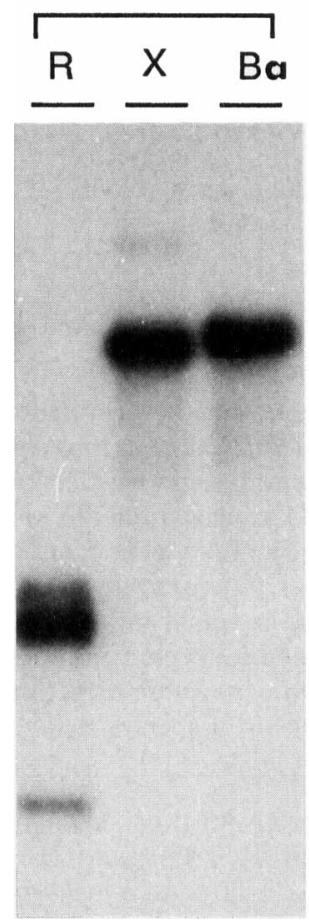

B

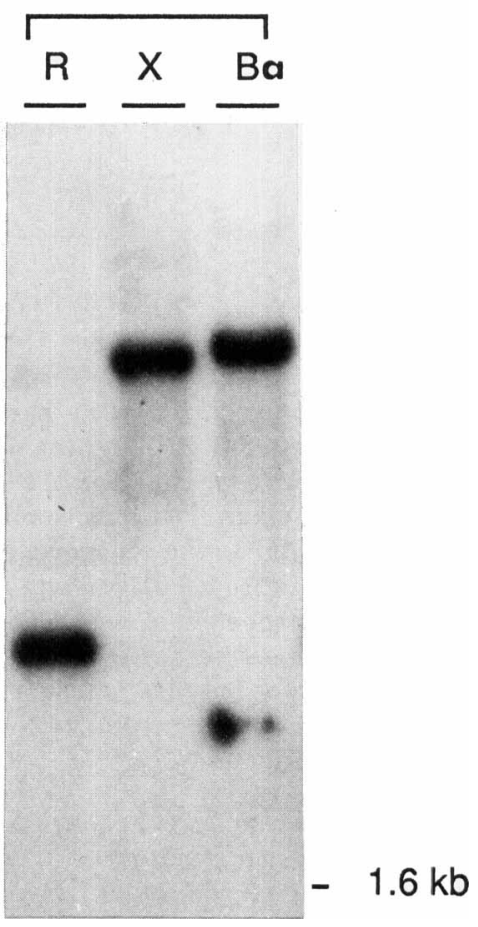

FIG. 2. Genomic DNA of strain ATCC 34873 digested with EcoRI (lanes R), XhoI (lanes X), and BamHI (lanes Ba) and fractionated by gel electrophoresis. The Southern blot of the genomic DNA was hybridized with pBIR6, a Cryptococcus neoformans rDNA cluster probe (A), and with the 5S rRNA oligonucleotide probe (B).

FIG. 1. Chromosomal location of rRNAs in Filobasidiella neofor mans as determined by separating chromosomes (by CHEF gel electrophoresis) and probing with plasmid pBIR6 containing the Cryptococcus neoformans rDNA cluster. Lanes 1, ethidium bromidestained strain ATCC 34873 (= B-3501) chromosomal banding pattern; lanes 2, Southern blots of the CHEF gel hybridized with pBIR6 (A) and the 5S rRNA oligonucleotide probe (B).

Mapping of rRNA genes. To map the boundaries of all four rRNA genes within the 8.6-kb fragment, the complete sequences of $18 \mathrm{~S}$ and $25 \mathrm{~S}$ rDNAs were obtained from Arturo Casadeval. The sequence of 5.8S rRNA was obtained from GenBank (accession number M94516).

\section{RESULTS}

Location of the 5S rRNA gene. Southern hybridization was carried out to determine whether the 5S rRNA gene in Filobasidiella neoformans is randomly distributed, as is the case in $N$. crassa and several other ascomycetous fungi, or is located within the repeat unit that encodes the $18 \mathrm{~S}, 5.8 \mathrm{~S}$, and $25 \mathrm{~S}$ rRNAs. A CHEF blot was hybridized with plasmid pBIR6 (containing an 8.6-kb rDNA insert) and an oligonucleotide that represented the highly conserved 5S rRNA gene sequence in heterobasidiomycetous yeasts (34) closely related to Filobasidiella neoformans. Both probes hybridized to chromosome 2 (Fig. 1) (37). The Southern hybridization patterns of genomic DNA from strain B-3501 digested with EcoRI, BamHI, and $X h o I$ (Fig. 2) were similar to each other when the preparations were probed with pBIR6 or $5 \mathrm{~S}$ rRNA oligonucleotides, indicating that the 5S rRNA gene is clustered with the genes on pBIR6. To determine the location of the 5S rRNA gene on the 8.6-kb rDNA insert, plasmid pBIR6 was digested with EcoRI, $B a m \mathrm{HI}$, and BglII and analyzed by Southern blot hybridization

by using oligonucleotides from the $5 \mathrm{~S}$ rDNA sequences. The probe hybridized with a $1.8-\mathrm{kb}$ EcoRI fragment and Bam HI fragment larger than $6 \mathrm{~kb}$, as well as with $B g l \mathrm{II}$ fragments (Fig. 3 ), which indicated that the $5 \mathrm{~S}$ rRNA gene is located on the left side of the first BglII site on the map shown in Fig. 4A. To determine the exact site of the 5S rRNA gene, pBIR6 was digested with EcoRI as well as with EcoRI plus PvuII and subjected to a Southern hybridization analysis performed with the $5 \mathrm{~S}$ oligonucleotide probe. The $1.8-\mathrm{kb}$ EcoRI fragment and the 1.4-kb EcoRI-PvuII fragment hybridized with the 5S rRNA probe (Fig. 5), indicating that the 5S rRNA gene is located between the $P v u$ II site and the first $E c o$ RI site on the $8.6-\mathrm{kb}$ insert (Fig. 4A). The 1.4-kb EcoRI-PvuII fragment was cloned into pBluescript II (Stratagene) and was sequenced to confirm the presence of the 5S rRNA gene.

Arrangement of rRNA genes in the 8.6-kb fragment. The restriction map of the $8.6-\mathrm{kb}$ rDNA fragment published previously (21), together with the total sequence of the 5S rDNA (this study), 18S rDNA (7), 5.8S rDNA (18), and 25S rDNA (7), allowed us to determine the boundaries of the four rRNA genes in the Cryptococcus neoformans rDNA repeat. Figure 4 shows a comparison of our map with the previously published map (21). The 5S rRNA gene is located about $1 \mathrm{~kb}$ upstream from the 18S rRNA gene. The distance between the coding regions of the $18 \mathrm{~S}$ and $5.8 \mathrm{~S}$ rRNAs and the coding regions of the $5.8 \mathrm{~S}$ and $25 \mathrm{~S}$ rRNAs was less than 200 bases. The DNA sequence indicated that the direction of transcription of the $5 \mathrm{~S}$ rRNA gene was the same as the direction of transcription of the 18S-5.8S-25S rRNA transcriptional unit.

Sequence comparisons of the $5 S$ rRNA gene. The oligonu- 


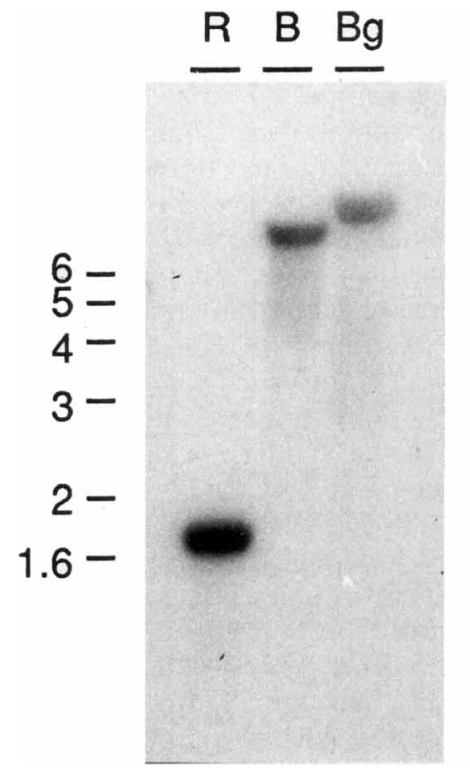

FIG. 3. To determine the arrangement of the 5S rRNA gene in the rDNA cluster, plasmid pBIR6 DNA was digested with EcoRI (lane R), $B a m \mathrm{HI}$ (lane $\mathrm{B}$ ), and $\mathrm{BglII}$ (lane $\mathrm{Bg}$ ), fractionated by gel electrophoresis, transferred to a nylon membrane, and hybridized with the $5 \mathrm{~S}$ rRNA oligonucleotide probe. The numbers on the left denote molecular size (in kilobases).

cleotide probe used in this study was constructed by using the highly conserved regions (positions 71 to 118 ) of the 5S rRNA genes of Filobasidium capsuligenum and Filobasidium floriforme, which are considered to be the organisms that are most closely related to Filobasidiella neoformans in the family Filobasideaceae (16). The sequence in this region is identical in Filobasidium capsuligenum and Filobasidium floriforme (Fig. 6). As is the case for the two Filobasidium species, there were 118 nucleotides in the 5S rRNA gene of Filobasidiella neoformans. The difference between the genus Filobasidiella and the genus Filobasidium was reflected in the sequence of the gene since there were four nucleotide differences between the two genera within the conserved region from nucleotide position

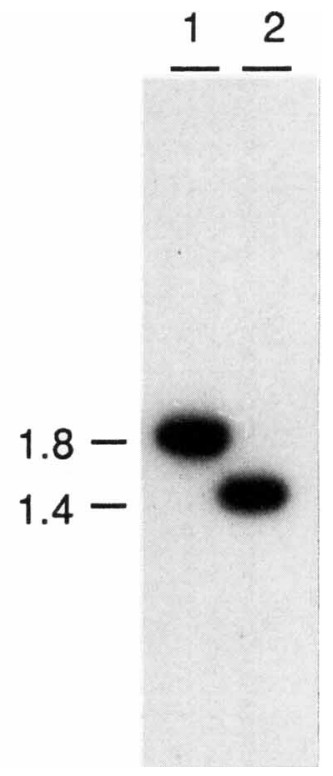

FIG. 5. EcoRI-digested (lane 1) and EcoRI-PvuII-digested (lane 2) plasmid pBIR6 DNAs hybridized with the 5S rRNA oligonucleotide probe to show the location of the $5 \mathrm{~S}$ rRNA gene. The numbers on the left denote molecular size (in kilobases).

71 to nucleotide position 118 . There were only three nucleotide differences between the two Filobasidium species in the total 5S rRNA gene sequence, while there were 28 and 29 nucleotide differences between the two Filobasidium species and Filobasidiella neoformans.

\section{DISCUSSION}

Although the sequences of $5 \mathrm{~S}$ rRNAs have been reported for numerous species of heterobasidiomycetous yeasts (1-3, $14,33-35,38$ ), the location of the 5S rRNA gene has not been investigated in this group of fungi. The 5S rRNA gene of Filobasidiella neoformans is within the rDNA repeat unit, as is the case for Mucor racemosus (10), Torulopsis utilis (24), Saccharomyces cerevisiae $(19,26)$, several other ascomycetous

A

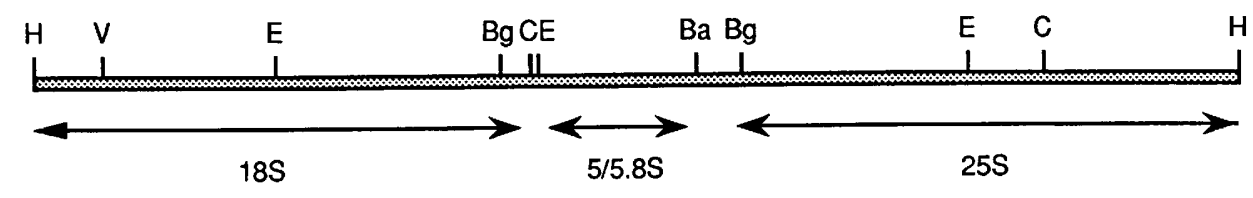

B

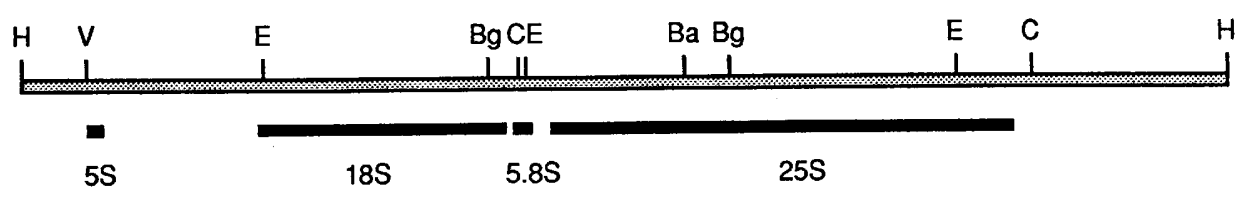

FIG. 4. (A) Restriction map showing the arrangement of Cryptococcus neoformans rRNA genes in pBIR6 as reported by Restrepo and Barbour (21). (B) Organization of rRNA genes determined in this study. Abbreviations: Ba, BamHI; Bg, BglII; C, ClaI; E, EcoRI; H, HindIII; V, PvuII. 
yeasts $(27,30,31)$, various Holobasidiomycetes that have been examined $(6,8,9,11,32)$, and several species of Oomycetes $(15,22)$. In Saccharomyces cerevisiae and Torulopsis utilis, the direction of transcription of the 5S rRNA gene is opposite the direction of transcription of the 18S-5.8S-25S rRNA unit. The direction of transcription of the $5 \mathrm{~S}$ gene in $M$. racemosus has not been determined. As in Filobasidiella neoformans, the 5S rRNA genes in the majority of the Holobasidiomycetes species that have been analyzed are transcribed in the same direction as the other rRNA subunits $(6,8,9,11,32)$. One exception is Coprinus comatus (9), in which the 5S rRNA gene and the other rRNA genes are oriented in opposite directions. In various species of the genera Phytophthora and Saprolegnia (water molds) the 5S rRNA gene is transcribed in the same direction as the 18S-5.8S-25S rRNA transcriptional unit (15). It is evident, therefore, that the organization of the $5 \mathrm{~S}$ rRNA gene exhibits divergence among the fungi, and the direction of the transcription does not appear to be uniform within each phylum. It is noteworthy, however, that all of the fungi studied so far and found to have the 5S rRNA genes scattered in the genome belong to the Ascomycota. The scattered pattern of the 5S rRNA genes, therefore, may be a useful genetic marker for ascomycetes.

Depending on the length of the spacer sequences between the 5S rRNA gene and the three other rRNA genes, the 5S rRNA gene can be closer to either the 18S rRNA gene or the $25 \mathrm{~S}$ rRNA gene in the rDNA repeat unit. The $5 \mathrm{~S}$ rRNA gene of Filobasidiella neoformans is located closer to the 18S rRNA subunit, while the 5S rRNA genes of all of the Holobasidiomycetes that have been tested thus far are located closer to the $25 \mathrm{~S}$ rRNA subunit $(6,8,9,11,32)$.

Restrepo and Barbour isolated RNA from Cryptococcus neoformans, electrophoresed it on $1 \%$ agarose, and subjected it to Northern (RNA) blot hybridization by using the $8.6-\mathrm{kb}$ insert of plasmid pBIR6. The probe hybridized to the $25 \mathrm{~S}$ and $18 \mathrm{~S}$ rRNA subunits, but the 5S and 5.8S rRNAs were not detected on the blots (21). The $5 \mathrm{~S}$ and 5.8S rRNAs are too small to be detected when they are electrophoresed on $1 \%$ agarose but can be detected on an acrylamide gel containing urea (12).

In recent years, rRNA genes have been isolated from fungi by using PCR techniques $(15,18)$. Primers have been designed to clone the $5.8 \mathrm{~S}$ rRNA gene, as well as the small- and large-subunit rRNA genes of Filobasidiella neoformans (18). The 47-mer oligonucleotide which we used appeared to be the most useful probe for cloning not only the 5S rRNA gene of Filobasidiella neoformans but also the 5S rRNA genes of many species of Holobasidiomycetes. The 47-nucleotide sequences from position 71 to position 118 of the $5 \mathrm{~S}$ rRNAs of four mushroom species, Schizophyllum commune, Coprinus cinereus, Coprinus radiatus, and Bjerkandra adusta, exhibited 98 to $100 \%$ similarity with the nucleotide sequences of Filobasidium species (34). It was surprising that there was a 4-nucleotide difference (92\% similarity) between Filobasidium species and Filobasidiella neoformans in this region, while there was only a 2-nucleotide difference (96\% similarity) between Filobasidiella neoformans and Tremella mesenterica (34). Substantial divergence between the genus Filobasidium and Filobasidiella neoformans has also been revealed by the 5.8 rRNA gene sequences (18). In their recent comprehensive review, Boekhout et al. treated the family Filobasidiaceae as a member of the order Tremellales (4). Although our data corroborate the classification system of Boekhout et al., more fungi in the family Filobasidiaceae will have to be analyzed for their $5 \mathrm{~S}$ rRNA sequences before the phylogenetic significance of the 
sequence divergence among the members of the family can be assessed.

\section{ACKNOWLEDGMENTS}

We thank Bianca Restrepo for supplying plasmid pBIR6 and Arturo Casadevall for supplying the DNA sequences of the $18 \mathrm{~S}$ and $25 \mathrm{~S}$ rRNA genes.

\section{REFERENCES}

1. Blanz, P. A., and M. Gottschalk. 1984. A comparison of $5 \mathrm{~S}$ ribosomal RNA nucleotide sequences from smut fungi. Syst. Appl. Microbiol. 5:518-526.

2. Blanz, P. A., and M. Gottschalk. 1986. Systematic position of Septobasidium, Graphiola and other Basidiomycetes as deduced on the basis of their $5 \mathrm{~S}$ ribosomal RNA nucleotide sequences. Syst. Appl. Microbiol. 8:121-127.

3. Blanz, P. A., and M. Unseld. 1987. Ribosomal RNA as a taxonomic tool in mycology. Stud. Mycol. 30:247-258.

4. Boekhout, T., A. Fonseca, J. P. Sampaio, and W. I. Golubev. 1993. Classification of heterobasidiomycetous yeasts: characteristics and affiliation of genera to higher taxa of Heterobasidiomycetes. Can. J. Microbiol. 39:276-290.

5. Borsuk, P. A., M. M. Nagiec, P. P. Stepien, and E. Bartnik. 1982. Organization of the ribosomal RNA gene cluster in Aspergillus nidulans. Gene 17:147-152.

6. Buckner, B., C. P. Novotny, and R. C. Ullrich. 1988. Organization of the ribosomal RNA genes of Schizophyllum commune. Curr. Genet. 13:417-424.

7. Casadevall, A. 1993. Personal communication.

8. Cassidy, J. R., D. Moor, B. C. Lu, and P. J. Pukkila. 1984. Unusual organization and lack of recombination in the ribosomal RNA genes of Coprinus cinereus. Curr. Genet. 8:607-613.

9. Cassidy, J. R., and P. J. Pukkila. 1987. Inversion of 5S ribosomal RNA genes within the genus Coprinus. Curr. Genet. 12:33-36.

10. Cihlar, R. L., and P. S. Syphered. 1980. The organization of the ribosomal RNA genes in the fungus Mucor racemosus. Nucleic Acids Res. 8:793-804.

11. Duchesne, L. C., and J. B. Anderson. 1990. Location and direction of transcription of the 5S rRNA gene in Armillaria. Mycol. Res. 94:266-269.

12. Free, S. J., P. W. Rice, and R. L. Metzenberg. 1979. Arrangement of the genes coding for ribosomal ribonucleic acids in Neurospora crassa. J. Bacteriol. 137:1219-1226.

13. Garber, R. C., B. G. Turgeon, E. U. Selker, and O. C. Yoder. 1988. Organization of ribosomal RNA genes in the fungus Cochliobolus heterostrophus. Curr. Genet. 14:573-582.

14. Gottschalk, M., and P. A. Blanz. 1984. Highly conserved 5S ribosomal RNA sequences in four rust fungi and atypical 5S rRNA secondary structure in Microstroma juglandis. Nucleic Acids Res. 12:3951-3958.

15. Howlett, B. J., A. G. Brownlee, D. I. Guest, G. J. Adcock, and G. I. McFadden. 1992. The $5 \mathrm{~S}$ ribosomal RNA gene is linked to large and small subunit ribosomal rRNA genes in oomycetes, Phytophthora vignae, $P$. cinnamomi, $P$. megasperma f. sp. glycinea and Saprolegnia ferax. Curr. Genet. 22:455-461.

16. Kwon-Chung, K. J. 1987. Filobasidiaceae-a taxonomic survey. Stud. Mycol. 30:75-85.

17. Long, E. O., and I. B. David. 1980. Repeated genes in eukaryotes. Annu. Rev. Biochem. 49:727-764.

18. Mitchell, T. G., T. J. White, and J. W. Taylor. 1992. Comparison of 5.8S ribosomal DNA sequences among the basidiomycetous yeast genera Cystofilobasidium, Filobasidium and Filobasidiella. J. Med. Vet. Mycol. 30:207-218.

19. Nath, K., and A. P. Bollon. 1977. Organization of the yeast ribosomal RNA gene cluster via cloning and restriction analysis. J. Biol. Chem. 252:6562-6571.

20. Perry, R. P. 1976. Processing of RNA. Annu. Rev. Biochem. 45:605-629.

21. Restrepo, B. I., and A. G. Barbour. 1989. Cloning of $18 \mathrm{~S}$ and $25 \mathrm{~S}$ rDNAs from the pathogenic fungus Cryptococcus neoformans. J. Bacteriol. 171:5596-5600.

22. Rozek, C. E., and W. E. Timberlake. 1979. Restriction endonuclease mapping by crossed contact hybridization: the ribosomal RNA genes of Achlya ambisexualis. Nucleic Acids Res. 8:1567-1578.

23. Selker, E. U., C. Yanofsky, K. Driftmier, R. L. Metzenberg, B. Alzner-DeWeerd, and U. L. Raj Bhandary. 1981. Dispersed 5S RNA genes in $N$. crassa: structure, expression and evolution. Cell 24:819-828.

24. Tabata, S. 1980 . Structure of the 5-S ribosomal RNA gene and its adjacent regions in Torulopsis utilis. Eur. J. Biochem. 110:107-114.

25. Tabata, S. 1981. Nucleotide sequences of the 5S ribosomal RNA genes and their adjacent regions in Schizosaccharomyces pombe. Nucleic Acids Res. 9:6429-6437.

26. Valenzuela, P., G. I. Bell, A. Venegas, E. T. Swell, F. R. Masiarz, L. J. Digennaro, F. Weinberg, and W. J. Rutter. 1977. Ribosomal RNA gene of Saccharomyces cerevisiae. J. Biol. Chem. 252:81268135 .

27. Van Heerikhuizen, H., A. Ykema, J. Klootwijk, C. Gaillardin, C. Ballas, and P. Fournier. 1985. Heterogeneity in the ribosomal RNA genes of the yeast Yarrowia lipolytica: cloning and analysis of two size classes of repeats. Gene 39:213-222.

28. Varma, A., and K. J. Kwon-Chung. 1991. A rapid method to extract DNA from Cryptococcus neoformans. J. Clin. Microbiol. 29:810-812.

29. Varma, A., and K. J. Kwon-Chung. 1992. A DNA probe for strain typing in Cryptococcus neoformans. J. Clin. Microbiol. 30:29602967.

30. Verbeet, M. P., J. Klootwijk, H. van Heerikhuizen, R. Fontijn, E. Vreugdenhil, and R. J. Planta. 1983. Molecular cloning of the rDNA of Saccharomyces rosei and comparison of its transcription initiation region with that of Saccharomyces carlsbergensis. Gene 23:53-63.

31. Verbeet, M. P., H. van Heerikhuizen, J. Klootwijk, R. D. Fontijn, and R. J. Planta. 1984. Evolution of yeast ribosomal DNA: molecular cloning of the rDNA units of Kluyveromyces lactis and Hansenula wingei and their comparison with the rDNA units of other Saccharomycetoideae. Mol. Gen. Genet. 195:116-125.

32. Vilgalys, R., and D. Gonzales. 1990. Organization of ribosomal DNA in the basidiomycete Thanatephorus praticola. Curr. Genet. 18:277-280.

33. Walker, W. F. 1984. 5S rRNA sequences from Atractiellales, and basidiomycetous yeasts and fungi imperfecti. Syst. Appl. Microbiol. 5:448-456.

34. Walker, W. F., and W. F. Doolittle. 1982. Redividing the basidiomycetes on the basis of $5 \mathrm{~S}$ rRNA sequences. Nature (London) 299:723-724.

35. Walker, W. F., and W. F. Doolittle. 1983. 5S rRNA sequences from eight basidiomycetes and fungi imperfecti. Nucleic Acids Res. 11:7625-7630.

36. Weinmann, R., and R. G. Roeder. 1974. Role of DNA-dependent RNA polymerase III in the transcription of tRNA and 5S RNA genes. Proc. Natl. Acad. Sci. USA 71:1790-1794.

37. Wickes, B. L., T. D. E. Moor, and K. J. Kwon-Chung. Comparison of the electrophoretic karyotypes and chromosomal location of ten genes in the two varieties of Cryptococcus neoformans. Microbiology, in press.

38. Wolters, J., and U. A. Erdmann. 1988. Compilation of 5S rRNA gene sequences. Nucleic Acids Res. 16S:r1-r70. 